\title{
Self-Reported Oral Hygiene Habits amongst Visually Impaired Students
}

\author{
Dr. Prahi Nayak, ${ }^{1}$ Dr. Aditi Mathur, ${ }^{1}$ Dr. Neema Shetty, ${ }^{1}$ Dr. Barkha Makhijani, ${ }^{1}$ \\ Dr. Ashish Bali, ${ }^{1}$ Dr. Balaji Manohar ${ }^{1}$ \\ ${ }^{1}$ Department of Periodontics, Pacific Dental College, Udaipur, Rajasthan, India.
}

\begin{abstract}
Introduction: Good oral hygiene provides a basis for good oral health and is important for prevention and treatment of oral conditions in children. Hence, it is essential to provide knowledge and treatment at regular intervals to the visually impaired individuals.

Objective: To evaluate the oral hygiene practices of visually impaired students attending a blind school with the help of a questionnaire.

Methods: The oral hygiene practices were evaluated in visually impaired students between the ages of 6 years to 22 years. A total of 92 students were enrolled from a blind school in Udaipur. The oral hygiene practice was assessed by a questionnaire survey.

Results: About $96.7 \%$ of the students brushed their teeth daily out of which $94.3 \%$ brushed their teeth with the help of a toothbrush and toothpaste. Majority of them brushed once a day in the morning. A total of $39.1 \%$ of the students cleaned their tongue also. All the students brushed alone without any guidance or supervision.

Conclusion: Although the blind students cannot see, they still practice good oral hygiene.

Keywords: Oral hygiene; questionnaire survey; visually impaired individuals.
\end{abstract}

\section{INTRODUCTION}

Oral health is considered to be an important factor when the general health and overall quality of life is evaluated. ${ }^{1}$ Dental plaque removal by the use of mechanical plaque control agents as a preventive step has shown to reduce the prevalence of caries and periodontal disease. ${ }^{2}$ Dental examination and prophylaxis are important for the prevention and diagnosis of oral disease. ${ }^{3}$

The dental health care team faces a special challenge when it encounters visually handicapped individuals. ${ }^{4}$ Less than $1 \%$ of the population is affected by blindness. ${ }^{5}$ Though visual impairment is highly prevalent in India, ${ }^{6}$ data regarding their dental health status and needs is sparse. Due to the visual impairment, the individual's oral health is compromised and a higher incidence of caries and gingival disease is seen. ${ }^{5}$

Good oral hygiene instruction is a pre-requisite for good oral health. The instructions include an explanation of the purpose of maintaining oral hygiene and inter dental cleaning through the use of visual aids. However; it is not possible to use a visual aid in blind or visually impaired indivuals. ${ }^{7}$ Keeping the above in mind, a study was designed to assess the oral hygiene habits in visually impaired students.

\footnotetext{
Correspondence:

Dr. Prahi Nayak

Department of Periodontics, Pacific Dental College, Udaipur, Rajasthan, India.

email:prahi_nayak@yahoo.com

\section{Citation}

Nayak P, Mathur A, Shetty N, Makhijani B, Bali A, Manohar B. SelfReported Oral Hygiene Habits amongst Visually Impaired Students. J Nepal Soc Perio Oral Implantol. 2019;3(5):6-8.
}

\section{METHODS}

A questionnaire study was conducted in the only blind school located in Udaipur where all the 92 students were enrolled in the study. The students were in the age group of 6 years to 22 years. They were further divided into various subgroups.

The students were enrolled in the study by organizing a dental camp after obtaining the ethical clearance to conduct the study by the ethical committee of Pacific Dental College and Hospital, Udaipur. A verbal consent was also taken before starting the study from the students as well as the principal of the blind school. A structured questionnaire was formulated which consisted of nine questions. All the questions were asked to the students in their own language by the examiner. The questions mainly consists of their daily oral hygiene practices such as brushing habits and frequency, use of interdental aids or chemical agents as an adjunct to brushing as well as tongue cleaning habits. All the questions were close-ended (Table 1). Statistical analysis was done by the Student ' $\mathrm{t}$ ' test to assess the responses obtained from the questionnaire.

\section{RESULTS}

A total of 92 blind students were enrolled in the questionnaire study out of which 90 students were males and only 2 were females. The students were further divided into subgroups on the basis of their age (Table 1).

Tooth brushing: From amongst the students who were enrolled in the study, 89 (96.7\%) of them brushed their teeth daily. The remaining 3 (3.3\%) students brushed their teeth occasionally. 
Table 2: PPD at baseline, 3 and 6 months after NSPT and OFD.

\begin{tabular}{|c|c|c|c|c|c|c|}
\hline \multirow{2}{*}{ Question } & \multirow{2}{*}{ Answer } & \multicolumn{5}{|c|}{ Age Groups (years) n(\%) } \\
\hline & & $6-8$ & $9-11$ & $12-14$ & $15-18$ & $19-22$ \\
\hline \multirow{3}{*}{ Do you brush daily? } & Yes & $0(4.3)$ & $12(13)$ & $26(28.3)$ & $37(40.2)$ & $10(10.9)$ \\
\hline & No & - & - & - & - & - \\
\hline & Occasionally & - & - & $2(2.2)$ & $1(1.1)$ & - \\
\hline \multirow{4}{*}{$\begin{array}{l}\text { What do you use for brushing } \\
\text { your teeth? }\end{array}$} & Brush and paste & $3(3.3)$ & $11(11.9)$ & $24(26.1)$ & $36(39.1)$ & $10(10.9)$ \\
\hline & Finger and paste & - & - & - & - & - \\
\hline & Brush and toothpowder & - & - & - & - & - \\
\hline & Finger and toothpowder & $1(1.1)$ & $1(1.1)$ & $4(4.3)$ & $2(2.2)$ & - \\
\hline \multirow{3}{*}{$\begin{array}{l}\text { How many times do you brush } \\
\text { in a day? }\end{array}$} & Once & $4(4.3)$ & $8(8.7)$ & $23(25)$ & $32(34.8)$ & $7(7.6)$ \\
\hline & Twice & - & $4(4.3)$ & $5(5.4)$ & $6(6.5)$ & $3(3.3)$ \\
\hline & More than twice & - & - & - & - & - \\
\hline \multirow{2}{*}{ How do you brush your teeth? } & Horizontal scrub & $4(4.3)$ & $12(13)$ & $28(30.4)$ & $38(41.3)$ & $10(10.9)$ \\
\hline & Vertical & - & - & - & - & - \\
\hline \multirow{2}{*}{ Do you use interdental aid? } & No & $4(4.3)$ & $12(13)$ & $28(30.4)$ & $38(41.3)$ & $10(10.9)$ \\
\hline & Yes & - & - & - & - & - \\
\hline \multirow{3}{*}{ Do you clean your tongue? } & Yes & - & - & $12(13)$ & $20(21.7)$ & $4(4.3)$ \\
\hline & No & $4(4.3)$ & $3(3.3)$ & $9(9.9)$ & $14(15.2)$ & $2(2.2)$ \\
\hline & Occasionally & - & $9(9.9)$ & $7(7.6)$ & $4(4.3)$ & $4(4.3)$ \\
\hline \multirow{2}{*}{ Do you use mouthwash? } & Yes & - & - & - & - & - \\
\hline & No & $4(4.3)$ & $12(13)$ & $28(30.4)$ & $38(41.3)$ & $10(10.9)$ \\
\hline \multirow{2}{*}{$\begin{array}{l}\text { Do you brush on your own } \\
\text { or under guidance of another } \\
\text { person? }\end{array}$} & On own & $4(4.3)$ & $12(13)$ & $28(30.4)$ & $38(41.3)$ & $10(10.9)$ \\
\hline & Under guidance & - & - & - & - & - \\
\hline
\end{tabular}

Material used for tooth brushing: 84 (94.3\%) students brushed their teeth with the help of toothbrush and toothpaste. Maximum students belonged to the $15-18$ years age group followed by the 12 - 14 years age group. The remaining 8 (5.7\%) students used their finger and tooth powder to brush their teeth.

Frequency of brushing: Majority of the students, that is, 74 (83.1\%) brushed their teeth once daily. Four students from 9 - 11 years age group, five from 12 - 14 years age group, six from the 15 - 18 years age group and three from the $19-22$ years age group brushed their teeth twice daily.

Method of tooth brushing: All the 92 students enrolled, brushed their teeth by the horizontal scrub method.

Use of interdental aid for plaque control: None of the 92 students used any interdental aid as an adjunct for plaque control.

Tongue cleaning: 36 (39.1\%) students cleaned their tongue daily. The maximum students belonged to the $15-18$ years age group (20 students). Twelve students in the $12-14$ years age group and four from the 19 - 22 years age group also cleaned their tongue daily. Nine students in the 9 - 11 years age group cleaned their tongue occasionally. None of the students in the age group of $6-8$ years cleaned their tongue.

Use of chemical aid for plaque control: None of the students in any of the age group used any form of chemical plaque control.

Supervised plaque control: All the 92 students performed plaque control on their own without any supervision

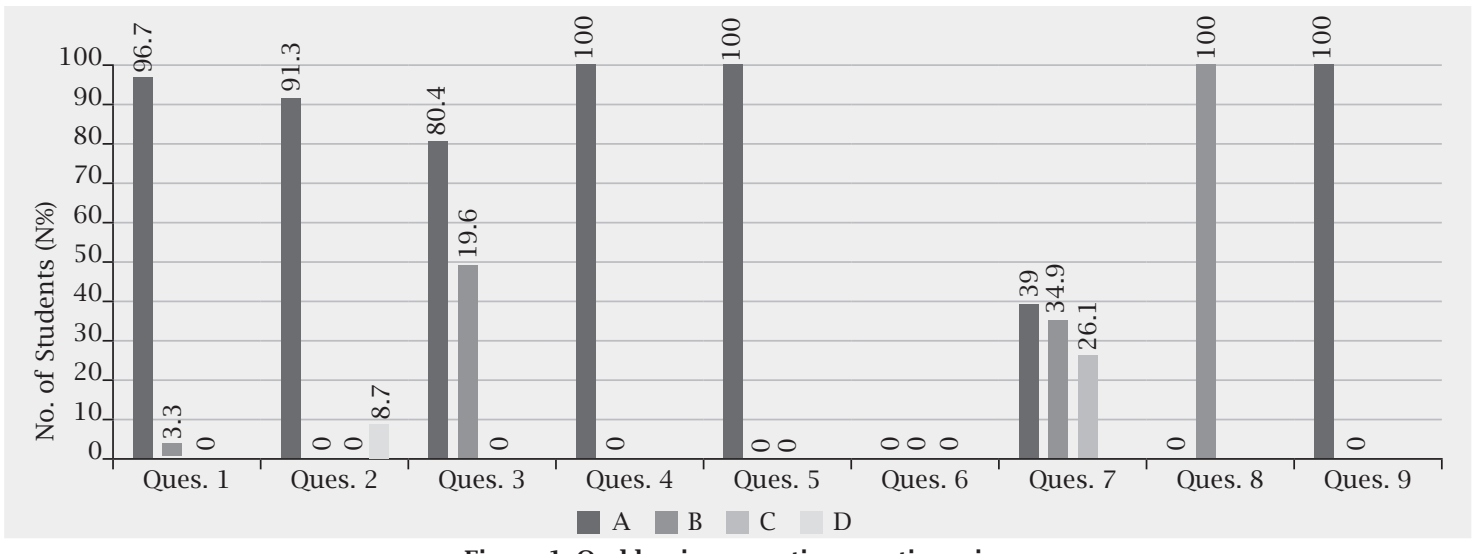

Figure 1: Oral hygiene practice questionnaire. 


\section{DISCUSSION}

Providing health care for differently abled individuals has always been a challenge. The society's misconception about a differently abled individual has led to pity, ignorance or being shied away from the society. This has made it even more difficult for health care professionals to deliver essential health care to these individuals. ${ }^{8}$

The differently abled individuals are entitled to the same standards of health and care as the general population. But still, these individuals experience poorer general as well as oral health that leads to unmet health needs and lower uptakes of screening services. ${ }^{9}$ It is a right, rather than a privilege for any individual to receive oral health and quality oral health care. ${ }^{10}$

Visual impairment affects the physical, social or informational barriers which leads to lack of custom ised information. ${ }^{11}$ In this study, the oral hygiene practices of all the subjects were consistent. Most of the students used a toothbrush and toothpaste for mechanical plaque control, and only 8 subjects were occasional users of mechanical plaque control aids (i.e. they used finger and tooth powder). As the students lived in an institutional setup in which caretakers enforce mandatory oral-hygiene routine, they brushed daily with a brush and toothpaste.

This study shows that $96.7 \%$ of the blind students used a tooth brush and a tooth paste as a plaque control agent for maintaining daily oral hygiene. Studies that were conducted by Jain et al, ${ }^{12}$ Azrina et al, ${ }^{13}$ Ahmad et al, ${ }^{14}$ and Nandini ${ }^{15}$ also concluded that most of the blind individuals used a tooth brush and a tooth paste for maintaining oral hygiene.

Approximately $80 \%$ of the blind students brushed their teeth only once a day by horizontal scrub method. They rarely used interdental aids and mouthwashes as an adjunct to mechanical plaque control. These results were in confirmation with the study conducted by Ahmad et al. ${ }^{14}$ As the visually impaired individuals cannot visualise the deposits on tooth surface, they need regular dental screening visits, education and motivation regarding oral health, oral hygiene measures and its impact on oral as well as overall health. There is utmost need to conduct oral health programs in these residential set-ups of visually impaired individuals. ${ }^{14}$ It has also been observed that visually impaired individuals tend to have a greater anxiety level with respect with dental treatment. And this will only lead to an adverse effect on the frequency of their dental visits and subsequently their oral health. ${ }^{16}$

Since this is a self-reported questionnaire-based study, there are chances of reporting bias. Also, the results may not be completely reliable as the responses were not validated by any clinical or radiographic parameters. The study was carried out among limited number of students in a single school as it was the only school for blind students in the area.

\section{CONCLUSION}

This study has led us to conclude that although the blind students cannot see, they still practice good oral hygiene. The fact that they are all living in an institution may play a major role in the enforcement of their oral hygiene practices. But the study also shows that a few students do not follow daily tooth brushing. Dental health education and motivation play a key role in improving this. A thorough dental health education with emphasis on the needs and learning abilities of the blind should be advocated by the dentists and healthcare providers. These individuals can be managed well with adequate training and alterations in dentist's routine preventive and treatment protocols. As a dental healthcare professional, it is our responsibility to provide comprehensive dental care to the visually impaired individual.

\section{REFERENCES}

1. Petersen PE, Kwan S. Evaluation of community- based oral health promotion and oral disease prevention - WHO recommendations for improved evidence in public health practice. Community Dent Health. 2004;21:319-29.

2. Al-Shammari, Al-Ansari, Al-Khabbaz, Dashti, Honkala. Self-Reported Oral Hygiene Habits and Oral Health Problems of Kuwaiti Adults. Med Princ Pract. 2007;16:15-21.

3. Axelsson P, Lindhe J. The significance of maintenance care in the treatment of periodontal disease. J Clin Periodontol. 1981;8:281-94.

4. D'Wis WB. Dental problems of the handicapped child. In: McDonald RE (cd.): Dentistry for the child and adolescent. C. V. Mosby, St. Louis. 1969;413.

5. Greeley CB, Goldstein PA, Forrester DJ. Oral manifestation in a group of blind students. J Dent Child. 1976:26:39-41.

6. Dandona R, Dandona L, Srinivas M, Girdhar P, Prasad MN, Vilas K, McCarty CA, Rao GN. Moderate visual impairment in India: The Andhra Pradesh eye disease study. Br J Ophthalmol. 2002;86:373-7.

7. Solanki J, Gupta S, Chand S. Comparison of dental caries and oral hygiene status among blind school children and normal children, Jodhpur city Rajasthan, India. Univ Res J Dent. 2014;4:22-5.

8. Jain M, Bharadwaj SP, Kaira LS, Chopra D, Prabhu D, Kulkarni S. Oral health status and treatment need among institutional ised hearingimpaired and blind children and young adults in Udaipur, India. A comparative study. Oral Health Dent Manag. 2013;12:41-9.

9. British society for disability and oral health. Clinical guidelines and integrated care pathways for the oral health care of people with learning disabilities 2001. London: The Royal College of Surgeons of England. 2001;1-56.

10. Clark CA, Vanek EP. Meeting the health care needs of people with limited access to care. J Dent Educ. 1984;48:213-6.

11. Lebowitz EJ. An introduction to dentistry for the blind. Dent Clin North Am. 1964;18:651-9.

12. Jain A, Gupta J, Aggarwal V, Goyal C. To evaluate the comparative status of oral health practices, oral hygiene and periodontal status amongst visually impaired and sighted students. Spec Care Dentist. 2013;33:78-84.

13. Azrina AN, Norzuliza G, Saub R. Oral hygiene practices among visually impaired adolescents. Ann Dent Univ Malaya. 2007;14:1-6.

14. Ahmad MS, Jindal MK, Khan S, Hashmi SH. Oral health knowledge, practice, oral hygiene status and dental caries prevalence among visually impaired students in residential institute of Aligarh. J Dent Oral Hyg. 2009;1:22-6.

15. Nandini NS. New insights into improving the oral health of visually impaired children. J Indian Soc Pedod Prev Dent. 2003;21:142-3.

16. Gordon SM, Dionne RA, Snyder J. Dental fear and anxiety as a barrier to accessing oral health care among patients with special health care needs. Spec Care Dentist. 1998;18:88-92. 